\title{
Estudio da evolución da superficie agrícola na comarca da Terra Chá a partir de fotografía aérea histórica e mapas de usos, 1956-2004
}

Recibido: 15 Setembro 2008 / Aceptado: 16 Outubro 2008
(C) IBADER- Universidade de Santiago de Compostela 2008

Resumo O abandono da terra agrícola é un tema de plena actualidade en Galicia: existen traballos científicos que confirman a súa existencia, textos legais que falan da "continua perda de superficie agraria útil", e evidencias visuais para calquera observador atento. Non obstante, o problema atópase pendente de ser cuantificado e ubicado territorialmente, en grande medida porque a insuficiente desagregación espacial dos datos estatísticos dispoñibles sobre coberturas ou usos do solo non permite capturar a súa grande complexidade. Neste traballo achégase unha aproximación cartográfica ó problema tomando como base a escala municipal, dentro dunha das comarcas máis dinámicas do sector agrario galego, e cunha perspectiva temporal a medio prazo. Os resultados confirman a diminución da superficie agrícola da comarca, pero destaca o feito de que esa diminución se concentrou exclusivamente nunha parte dos concellos que a integran, mentres que o resto se mantiveron nos niveis de 1956 ou incluso os incrementaron. Deste resultado conclúese a necesidade de territorializar as políticas concebidas para combatir o abandono e as súas consecuencias negativas, de modo que se actúe principalmente nas áreas máis afectadas.

Palabras clave SAU · uso do solo - abandono de terras . sistemas de información xeográfica · fotografía aérea

Abstract Land abandonment has become a topical issue in Galicia: there are scientific works that confirm its existence, legal texts that mention the "continuous reduction of agricultural area", and enough visual evidence for any attentive observer. Nevertheless, the problem is far from being quantified and spatially located, largely because the spatial detail of the available statistical sources about land use and/or land cover is insufficient to capture its great

Eduardo Corbelle Rico · Rafael Crecente Maseda Departamento de Enxeñería Agroforestal. Escola Politécnica Superior. Universidade de Santiago de Compostela Campus Universitario s/n, 27002. Lugo. http://laborate.usc.es Tel. 982285900 , ext. 23292.

e-mail: eduardo.corbelle@usc.es spatial complexity. This paper approaches the problem from a cartographic perspective at municipal level, taking a group of municipalities usually considered as having a dynamic agriculture, and using a 50 year time-frame. The results confirm the decrease of agricultural area at the group level, but also point out that the decrease was concentrated on only a part of municipalities while the rest of them maintained levels that were equivalent to those of 1956 or even higher. Conclusions point towards the need for the spatial planning of measures intended to fight land abandonment and its consequences, so that they are tailored to the actual distribution of the problem.

Keywords UAA · land use and abandonment - geographic information systems · aerial photography

\section{Introdución}

A recente aprobación da Lei do Banco de Terras de Galicia (Lei 7/2007, do 21 de maio, de medidas administrativas e tributarias para a conservación da superficie agraria útil e do Banco de Terras de Galicia, DOG de 31 de maio) sitúa o problema do descenso da Superficie Agrícola Utilizada (SAU) na comunidade nun lugar importante e de dominio público, na medida en que este está directamente relacionado con algúns dos problemas de fondo do medio rural galego como, por exemplo, os incendios forestais, a diminución e envellecemento da poboación rural, ou a perda de agro-ecosistemas tradicionais de alto valor ecolóxico e paisaxístico. A literatura científica europea establece con claridade esta relación entre os procesos de marxinalización e abandono da agricultura e as consecuencias negativas de tipo social, ambiental e paisaxístico que conlevan (Baldock et al., 1996; MacDonald et al., 2000; EEA, 2004; Strijker, 2005; DLG, 2005). No caso galego foron os traballos realizados desde a economía agraria, apoiados fundamentalmente sobre os datos de sucesivos Censos Agrarios, os que resaltaron a existencia dunha continua diminución do número de explotacións que, combinada coa escasa transferencia da terra ás explotacións que se mantiveron en activo, daría como resultado o descenso 
progresivo da SAU e o relativo estancamento da superficie media das explotacións (López Iglesias, 1996, 2000). Non obstante, a información sobre usos/cubertas do solo procedente das diferentes fontes estatísticas (por exemplo os Anuarios de Estadística Agroalimentaria do Ministerio de Agricultura, os Anuarios de Estatística Agraria da Consellería de Medio Rural, ou os propios Censos Agrarios) non permite apoiar de maneira contundente afirmacións como as contidas no texto da Lei 7/07 acerca da "continua redución da superficie agraria útil", e en todo caso obriga a grandes matizacións. Por exemplo, o Censo Agrario de 1989 cifra a SAU galega en 675.038 ha, mentres que o correspondente a 1999 fala de 696.690 ha (INE, 2008a). De modo similar, os Anuarios do Ministerio tampouco indican unha tendencia clara ó descenso: 870.500 ha en 1980, 973.000 ha en 1989 , e preto das 874.000 ha en 2003 , por citar só algunhas (MAPA, 1981-2004). A fiabilidade das fontes, a maiores, é discutible: por exemplo os datos de superficie presente nos Censos son os declarados polos entrevistados, e entre os Anuarios só os da Consellería informan da metodoloxía empregada (que precisamente cambiou desde 2002 en adiante; Xunta de Galicia, 2003).

Non obstante, a existencia de procesos de abandono da actividade agrícola no noso territorio é evidente para calquera observador atento. A súa existencia si se reflicte nas fontes estatísticas cando se descende, por exemplo, ó nivel provincial: tanto os Anuarios do Ministerio como os Censos Agrarios permiten identificar a Ourense como a provincia con perda neta de SAU dentro da Comunidade Autónoma nas últimas décadas (INE, 2008a; MAPA, 19812004). Resulta evidente que os valores medios contidos nas estatísticas enmascaran un fenómeno complexo que ten lugar a diferentes escalas que van desde a explotación individual ata a parroquia, municipio, comarca e provincia, e que se distribúe de maneira irregular polo territorio. Isto leva a pensar que para un axeitado tratamento do problema -por exemplo, para dirixir as accións ás áreas máis afectadas- é necesario ter esta complexidade en conta e realizar un tratamento particular da cuestión, máis centrado na súa compoñente espacial. É dicir, trataríase de identificar a unha escala operativa (por exemplo municipal) as entidades que máis sufriron a perda de SAU.

\section{Obxectivos}

O traballo que se presenta toma unha área de estudo relativamente extensa e diversa como é a comarca da Terra Chá e analiza cunha perspectiva a medio prazo (aproximadamente 50 anos) a evolución seguida pola superficie ocupada pola agricultura. Interesa en particular someter a proba o hipotético descenso da SAU que tería sucedido, así como coñecer a súa distribución a escala municipal e as direccións de cambio operadas.

Conflúen neste traballo o concepto de SAU, entendido como a suma de terra arable, prados e pasteiros, e por outro lado o concepto, máis amplo, de superficie agrícola. A distinción é pertinente por canto a superficie utilizada pola agricultura na Galicia de mediados do século $X X$ incluía unha parte da superficie de mato, na súa función de aporte de pasto e estrume, e polo tanto era máis ampla que a SAU. Estrictamente, este traballo utiliza a variacion de SAU como un estimador das variacións da superficie agrícola.

\section{Área de estudio}

A comarca da Terra Chá está situada na provincia de Lugo (figura 1) e inclúe, segundo a definición establecida polo decreto que regula o mapa comarcal de Galicia (Decreto 65/1997, de 20 de febreiro, polo que se aproba definitivamente o mapa comarcal de Galicia), nove concellos: Abadín, Begonte, Castro de Rei, Cospeito, Guitiriz, Muras, A Pastoriza, Vilalba, e Xermade. A extensión dos diferentes municipios oscila entre os $127 \mathrm{~km}^{2}$ de Begonte e os $379 \mathrm{~km}^{2}$ de Vilalba, ata un total conxunto de $1822 \mathrm{~km}^{2}$.

Desde o punto de vista xeográfico, a comarca está formada por unha extensa chaira central, da que toma o nome, rodeada por un conxunto de formacións montañosas que a separan das comarcas veciñas: as serras de Cova da Serpe e da Loba polo oeste forman a fronteira coa provincia de $\mathrm{A}$ Coruña, as serras da Carba e do Xistral establecen o límite coa Mariña luguesa, e o Cordal de Neda e a serra de Meira forman o límite oriental. O conxunto da comarca constitúe unha área de drenaxe natural en dirección sur a través do

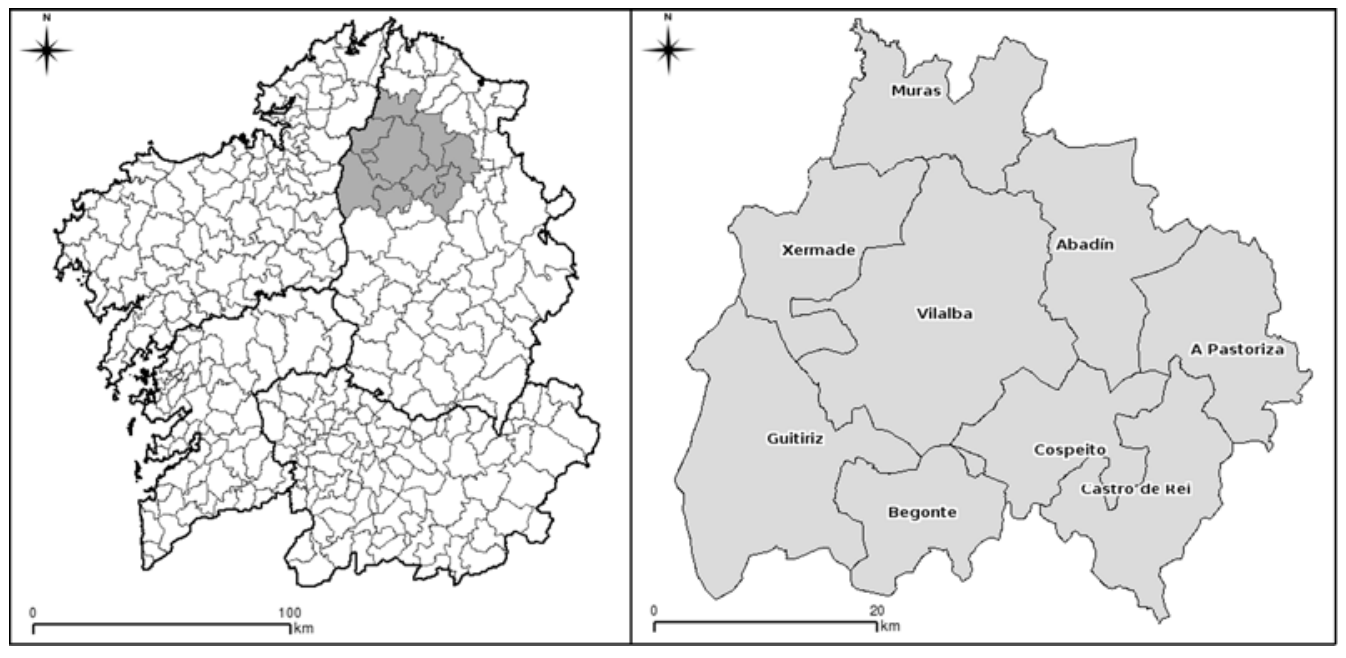

Figura 1.- Situación e concellos da comarca de Terra Chá 
río Miño e os seus afluentes. O interese da comarca para este traballo reside en varios factores: (a) está situada nunha provincia (Lugo) que de acordo coa información estatística existente non se viu seriamente afectada por un descenso de SAU nos últimos vinte anos (De acordo cos datos dos Anuarios de Estadística Agraria publicados polo MAPA, a SAU da provincia pasou de 308.100 ha en 1980 a 330.447 ha en 2003) (MAPA, 1981, 2004); (b) é unha comarca relevante - ata poderiamos dicir modelo- no proceso de especialización gandeira e "modernización" da agricultura galega (López Charques, 1997; Iglesias Patiño et al., 2000); e (c) foi unha das cinco comarcas inicialmente declaradas Zonas de Especial Interese Agrario (ZEIA) para o Banco de Terras de Galicia (Decreto 206/2007, de 25 de outubro, polo que se declaran como zonas de especial interese agrario as comarcas de Ordes, A Terra Chá, A Limia, Deza e Baixo Miño).

\section{Materiais}

O voo fotográfico de 1956-57

O voo de 1956-57 é resultado dos acordos comerciais e militares, iniciados arredor do ano 1943, firmados entre os gobernos de EEUU e España. Os militares norteamericanos realizaron dous voos fotográficos con cobertura completa do territorio español: o voo da serie A, realizado en 1945-1946 a escala 1:45.000, e o voo da serie B, feito en 1956-1957 a escala 1:30.000 (Fernández García \& Quirós Linares, 1997).

Este traballo baséase na hipótese de que o voo de 1956-57 proporciona unha boa imaxe do sistema agrario tradicional, entendido como previo á "revolución verde" da segunda metade do século XX. Ata que punto o sistema agrario xa sufrira transformacións na altura é difícil de afirmar, pero todas as fontes indican que o período de guerra civil e posguerra supuxo un freo á dinámica transformadora que comezara no primeiro tercio do século $X X$ e incluso unha pequena volta atrás, e que as novas transformacións non comezaron ata finais dos 50 ou primeiros dos 60 . No caso galego e en particular na Terra Chá está ben documentado como o sistema de rozas, a gandería extensiva e o sistema de "ano e vez" nas agras se mantiveron ata ben entrada a década de 1950 (Cardesín Díaz, 1992; Bouhier, 2001).

O mapa de usos e as ortofotografías do SIGPAC

Os datos de cobertura actual foron derivados do mapa de recintos do SIGPAC, correspondente ós anos 2003-2004. Tamén se utilizaron as ortofotografías do proxecto SIGPAC, para a fotointerpretación e como material de apoio na ortorrectificación das fotografías de 1956.

\section{Método}

Dixitalización e ortorrectificación da fotografía de 1956

O material fotográfico de 1956 estaba dispoñible na forma de copias de contacto dos negativos orixinais, en papel fotográfico convencional e cun grao de conservación aceptable. O voo sobre a provincia de Lugo foi realizado en pasadas na dirección leste-oeste e numeradas de norte a sur, de modo que a zona de traballo quedou recollida nas pasadas 6 a 18, tomadas en diferentes momentos comprendidos entre abril de 1956 e agosto de 1957 (figura 2).

As copias en papel dixitalizáronse empregando un escáner convencional tamaño $\mathrm{A} 3$, a unha resolución de $21 \mathrm{~mm} /$ píxel. Dada a escala de voo, a resolución espacial sitúase aproximadamente nos $60 \mathrm{~cm} /$ píxel. Posteriormente sometéronse a un proceso de ortorrectificación e mosaico co paquete informático Erdas Imagine 9.1, empregando como material de apoio un modelo dixital do terreo con malla de 5 metros derivado da cartografía 1:5000 e as ortofotografías dixitais do SIGPAC (anos 2003-2004 e erro medio cuadrático menor de $1,25 \mathrm{~m}$; MAPA, 2002). A calidade da ortorrectificación foi estimada mediante puntos de comprobación independentes, cun resultado en torno ós 5 metros de erro medio cuadrático, de modo que constitúe un produto cartográfico válido segundo os criterios máis habituais para unha escala de publicación de 1:20.000 (Corbelle Rico et al., 2006).

\section{Deseño da mostraxe}

Dada a grande extensión da área de estudo optouse por utilizar técnicas de mostraxe estatística, e non un inventario completo. Escollemos un esquema sistemático coa finalidade de asegurar un bo reparto sobre a superficie de estudio, unha aproximación similar á empregada noutros estudos de uso/cobertura do solo como o caso do proxecto da Unión Europea Land Use/Cover Area frame statistical Survey (LUCAS) (Martino \& Fritz, 2008). O deseño da mostra tomou a forma de malla cadrada de $500 \mathrm{~m}$ de lado, na que cada vértice define un punto de mostraxe (7.274 en total). En cada un destes puntos identificouse un círculo de $100 \mathrm{~m}^{2}$ (12 m de diámetro), e a cuberta existente obtívose por fotointerpretación para 1956 e directamente do mapa de recintos do SIGPAC para o ano 2003. As clases de cuberta identificadas reducíronse a catro, de maneira similar a outros traballos (Calvo Iglesias, 2005; Mottet et al., 2006; Millington et al., 2007; van Doorn \& Bakker, 2007): (1) terra arable, prados e pasteiros, (2) mato, (3) arborado, e (4) outras superficies.

\section{Fotointerpretación}

Para facilitar unha mellor comprensión dos tipos de cuberta existentes en 1956 e a súa distribución recorremos á descrición das formas de organización agraria realizada por Bouhier (2001), que no caso da área de traballo se corresponde a grandes rasgos coa área de "eidos de cerrados das montañas septentrionais" no caso do concello de Muras, e coa área dos "eidos de agras" no resto dos concellos. Desde o punto de vista do fotointérprete, a primeira delas representa a maior dificultade, debido á mistura confusa entre as áreas de labradío, pasteiros e mato que pode chegar a "despistar ó observador e ás veces 


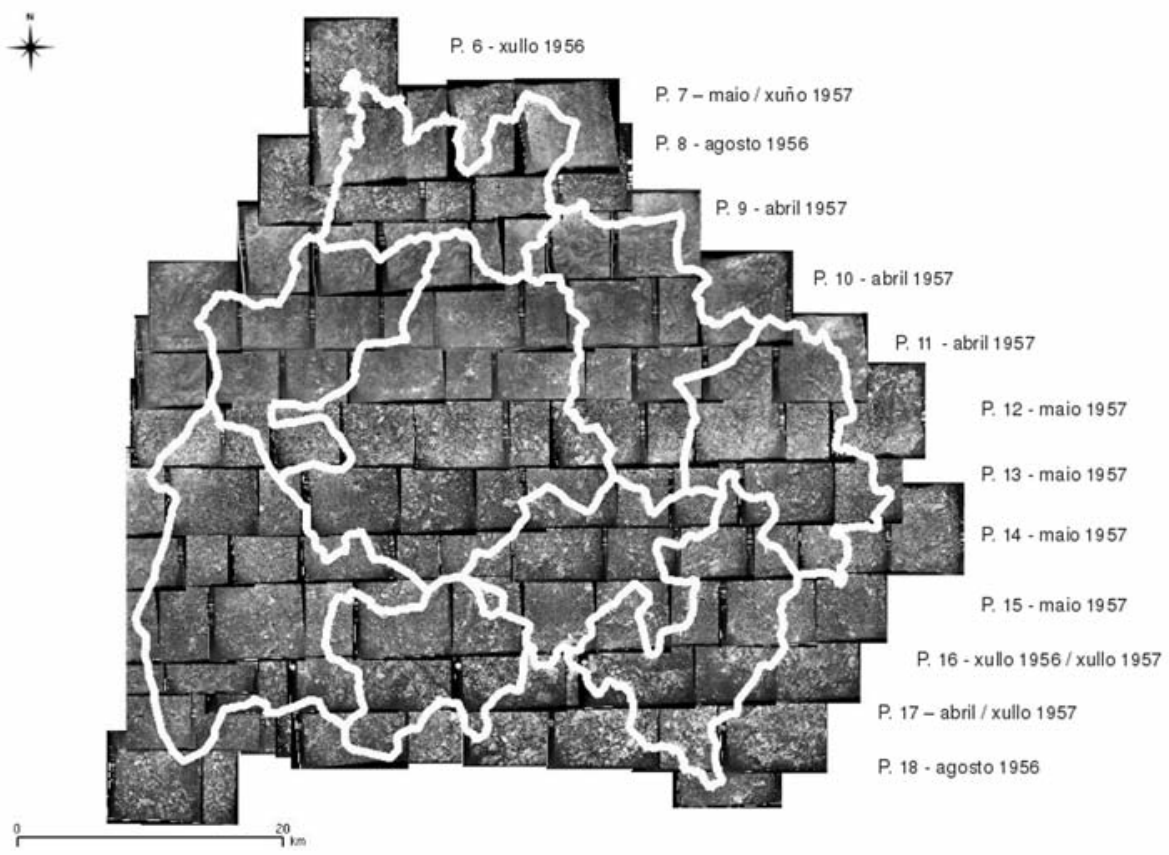

Figura 2.- Pasadas do voo de 1956-1957 sobre a área de estudio

ata ó propio utilizador" (Bouhier, 2001). A fotointerpretación das zonas de agras é máis simple, polo contrario, debido á presencia dos grandes bloques de cultivo (agras) facilmente indentificables. En ambos casos, unha dificultade adicional débese á coexistencia de diferentes graos de intensidade no aproveitamento do mato, que van desde as áreas de mato sementado, a miúdo na proximidade da explotación e en ocasións inserido na zona de agras, ata o mato que cubría áreas intermedias entre dúas parroquias, constituíndo en principio un terreo inculto pero "de vez en cando, furado por vastos bloques de cultivo, non cerrados, e traballados senón de xeito absolutamente definitivo, alomenos durante períodos longos ou bastante longos" (Bouhier, 2001). Esta diferenciación non afecta á identificación de cubertas, pero ten implicacións importantes á hora de estimar a superficie explotada pola agricultura en apartados posteriores. A figura 3 mostra un exemplo de identificación de diferentes cubertas nunha zona de agras.

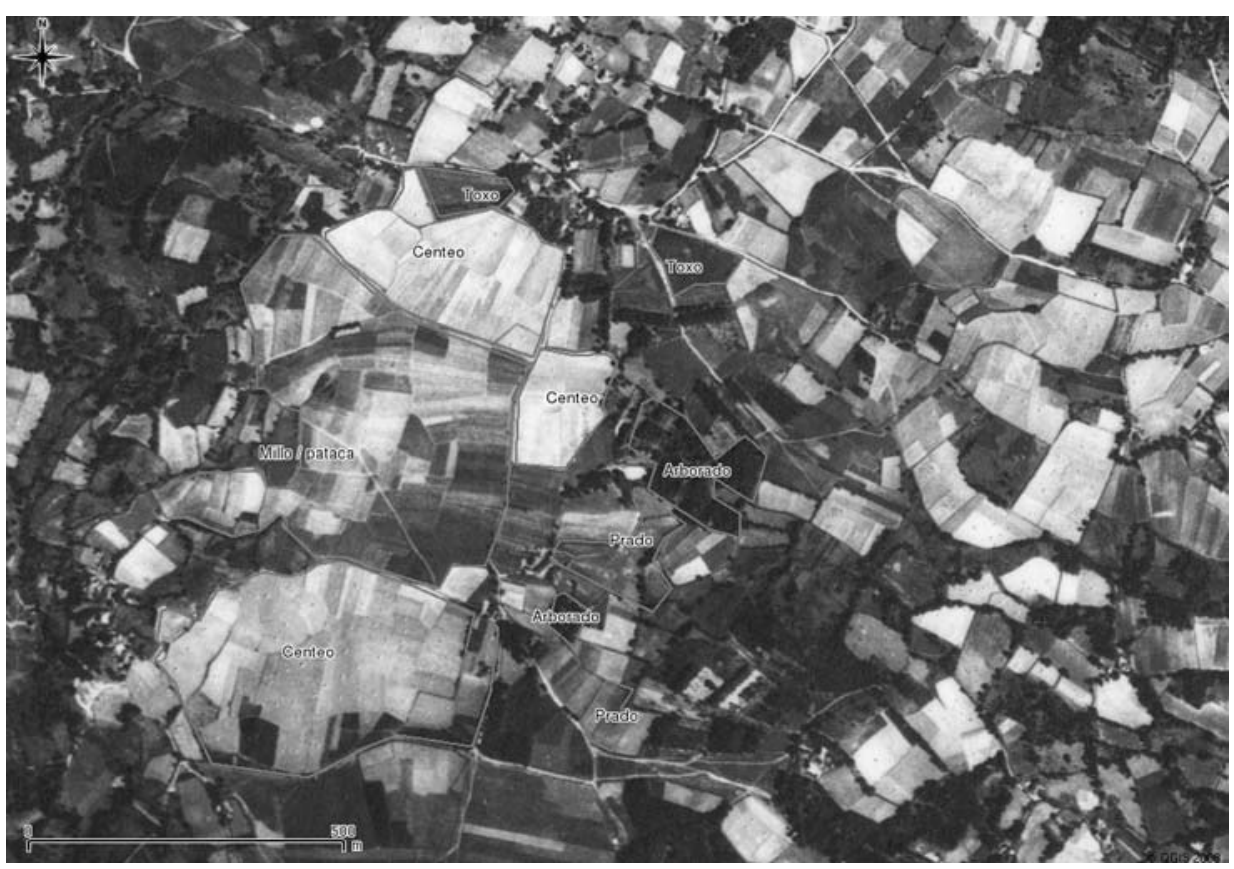

Figura 3.- Exemplo de interpretación de cubertas (Cerdeiras, Begonte, xullo de 1957) 


\begin{tabular}{lll} 
Uso SIGPAC & Cobertura asignada \\
\hline TA & Terra arable & Arable, prados e pasteiros \\
TH & Horta & Arable, prados e pasteiros \\
FY & Froiteira & Arable, prados e pasteiros \\
VI & Viñedo & Arable, prados e pasteiros \\
PS & Pasteiro & Arable, prados e pasteiros \\
PR & Pasto arbustivo & Mato \\
PA & Pasto arbustivo con arborado & Mato \\
FO & Forestal & Arborado \\
CA & Vias & Outras \\
AG & Correntes e superficies de auga & Outras \\
ZU & Zona urbana & Outras \\
ED & Edificacións & Outras \\
IM & Improdutivos & Outras \\
ZC & Zona concentrada non reflectida na ortofoto & Ningunha (fotointerpretada sobre orto de 2003) \\
\hline
\end{tabular}

Táboa 1.- Adaptación da lenda do SIGPAC

\section{Adaptación do mapa de recintos do SIGPAC}

Dado que a lenda de usos de SIGPAC é máis detallada que a que utilizamos neste traballo, era necesario simplificala. $O$ criterio seguido para adaptala aparece na táboa 1. Destaca ó final da táboa a categoría ZC ("Zona Concentrada non reflectida na ortofoto") sobre a que o SIGPAC non aporta datos de cuberta: para os puntos de mostraxe que caeron nestas zonas realizouse unha interpretación manual sobre a fotografía de 2003-2004.

\section{Resultados}

\section{Distribución das cubertas do solo}

Os resultados (figura 4) mostran unha paisaxe que en 1956 estaba dominada case a partes iguais pola superficie cultivada e a superficie de mato (arredor do $45 \%$ da

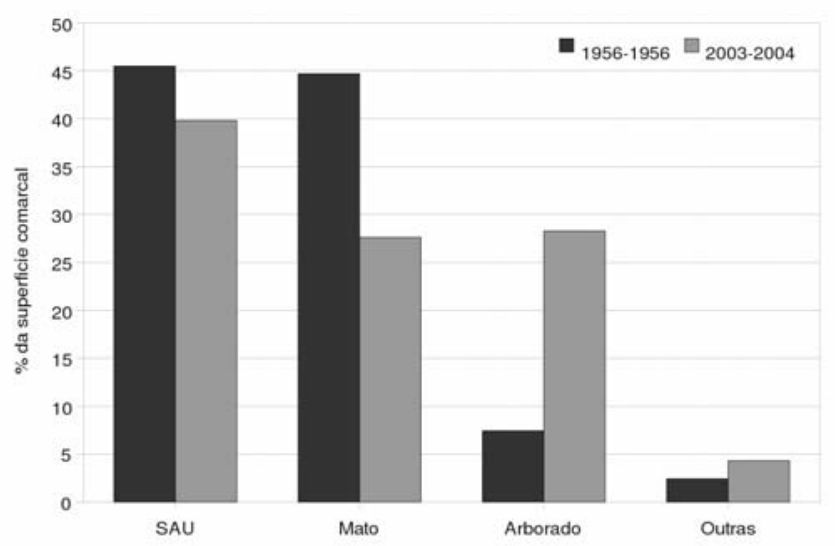

Figura 4.- Distribución das diferentes cubertas, 1956-57 e 2003-04 superficie comarcal) cunha presenza moi reducida das áreas cubertas por arborado (en torno ó $7 \%$ da superficie). Os datos de 2003-04 mostran un lixeiro descenso da superficie cultivada ( $40 \%$ da superficie comarcal), un descenso considerable da superficie de mato que a reduce case á metade (28\%), e un incremento notable da superficie cuberta por arborado ata igualar á de mato (28\%).

A nivel municipal a distribución da superficie ocupada polas diferentes cubertas segue un patrón similar (SAU e mato son as cubertas maioritarias en 1956-57) pero con certas diferencias entre concellos (táboa 2).

Para valorar a evolución seguida pola SAU de cada concello, e dado que os datos proceden de mostraxe, o criterio para decidir se a variación entre as proporcións observadas era significativa ou non foi o intervalo de confianza ó $95 \%$ calculado para cada ano segundo o método proposto por Goodman (1965) para distribucións multinomiais (figura 5). Como se pode observar na figura, existen diferencias significativas nos concellos de Begonte, Guitiriz, Muras, Vilalba e A Pastoriza, coa particularidade de que as variacións nos catro primeiros foron á baixa mentres que no último a SAU municipal se incrementou. Nos catro concellos restantes (Abadín, Castro de Rei, Cospeito e Xermade) existe solape entre os intervalos de confianza calculados para cada período, polo que non é posible afirmar que tivera lugar un cambio da superficie ocupada por SAU.

\section{Direccións de cambio}

A comparación das cubertas identificadas en cada punto da mostra nos dous anos de referencia permite detectar os cambios entre as diferentes superficies. A táboa 3 compara as superficies segundo o tipo de cuberta que tiveron en 1956-1957 (en filas) e a que presentaban en 2003-2004 (columnas). A suma de cada fila representa a superficie cuberta por unha determinada categoría en 1956-57 e a 


\begin{tabular}{lcccccc}
\hline \multirow{2}{*}{ Concello } & \multicolumn{2}{c}{ SAU (\%) } & \multicolumn{2}{c}{ Mato (\%) } & \multicolumn{2}{c}{ Arborado (\%) } \\
\cline { 2 - 6 } & $1956-57$ & $2003-04$ & $1956-57$ & $2003-04$ & $1956-57$ & $2003-04$ \\
\hline Abadín & 39,4 & 36,7 & 53,5 & 38,8 & 4,8 & 19,1 \\
Begonte & 58,0 & 27,3 & 30,0 & 19,4 & 8,7 & 44,2 \\
Castro de Rei & 53,0 & 55,0 & 35,8 & 13,7 & 7,6 & 27,6 \\
Cospeito & 63,0 & 63,0 & 26,2 & 9,1 & 7,9 & 20,8 \\
Guitiriz & 41,9 & 29,5 & 52,4 & 28,9 & 3,7 & 36,1 \\
Muras & 27,4 & 12,2 & 61,8 & 58,3 & 9,8 & 26,3 \\
A.Pastoriza & 46,6 & 57,7 & 46,5 & 18,7 & 3,8 & 19,8 \\
Vilalba & 50,7 & 43,3 & 36,6 & 26,2 & 10,5 & 28,3 \\
Xermade & 31,7 & 35,0 & 56,7 & 32,0 & 10,0 & 31,3 \\
\hline
\end{tabular}

Táboa 2.- Estimación da proporción de superficie municipal ocupada polas diferentes cubertas

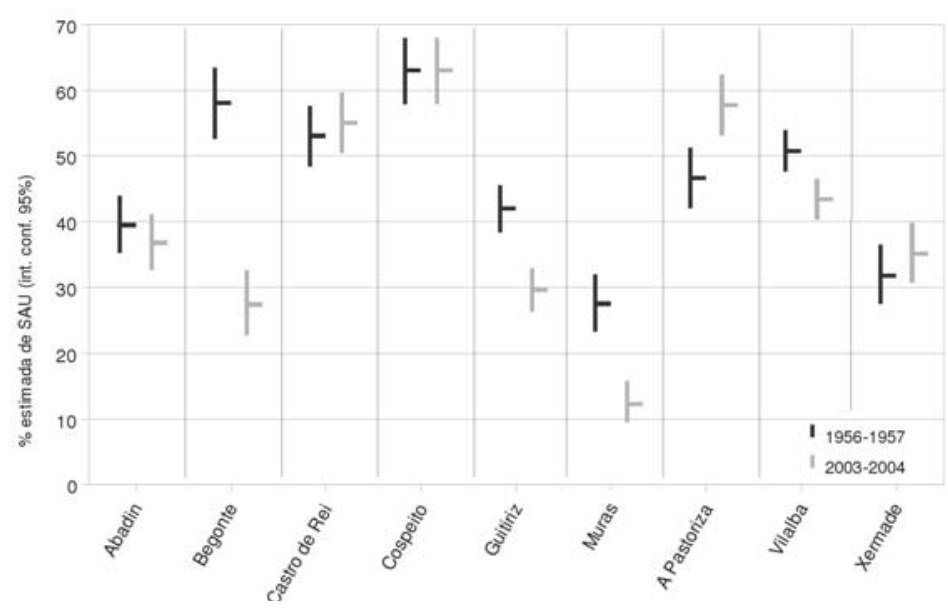

Figura 5.- Intervalos de confianza ó $95 \%$ para a SAU municipal

\begin{tabular}{|c|c|c|c|c|c|}
\hline \multirow{2}{*}{$1956-57$} & \multicolumn{4}{|c|}{ 2003-04 } & \multirow{2}{*}{ Total 1956-57 } \\
\hline & SAU & Mato & Arborado & Outras & \\
\hline SAU & $493(27,1 \%)$ & $119(6,6 \%)$ & $181(10,0 \%)$ & $36(2,0 \%)$ & $829(45,5 \%)$ \\
\hline Mato & $182(10,0 \%)$ & $364(20,0 \%)$ & $246(13,5 \%)$ & $22(1,2 \%)$ & $814(44,7 \%)$ \\
\hline Arborado & $37(2,0 \%)$ & $14(0,7 \%)$ & $79(4,4 \%)$ & $5(0,3 \%)$ & $135(7,4 \%)$ \\
\hline Outras & $14(0,7 \%)$ & $6(0,3 \%)$ & $9(0,4 \%)$ & $16(0,9 \%)$ & $45(2,4 \%)$ \\
\hline Total 2003-04 & $726(39.8 \%)$ & $503(27,6 \%)$ & $515(28,3 \%)$ & $79(4,3 \%)$ & $1822(100 \%)$ \\
\hline
\end{tabular}

Táboa 3.- Direccións de cambio no período 1956-2004 (km²)

suma dunha columna corresponde ó total de 2004. As cifras na diagonal da táboa representan as áreas que non mudaron de cuberta, e o resto das cifras representan a área que mudou dunha cuberta anterior (fila) a outra actual (columna), de modo que ó ler unha fila podemos ir descifrando o destino da superficie orixinal.

Da análise da táboa 3 destaca o feito de que a perda de SAU entre 1956 e 2004 se debe de modo maioritario á ocupación por arborado $\left(181 \mathrm{~km}^{2}\right)$, e en segundo lugar á colonización por mato $\left(119 \mathrm{~km}^{2}\right)$. Tamén se pode apreciar que amplas superficies de mato foron roturadas para soster un uso agrícola máis intensivo $\left(182 \mathrm{~km}^{2}\right)$, de modo que o balance de cambios entre mato e SAU é favorable a esta última. Non obstante, neste punto é necesario ter en conta que o uso de grande parte da superficie de mato en 1956-
57 tiña un carácter ben diferente do actual: hoxe é posible afirmar que as superficies cubertas por mato non soportan practicamente ningún tipo de aproveitamento, o cal non era certo cincuenta anos antes. É razonable pensar que grande parte dos $182 \mathrm{~km}^{2}$ de terras roturadas simplemente impliquen o paso dunha forma de aproveitamento agrogandeiro extensivo a outra máis intensiva e non sexan, en definitiva, terras gañadas pola agricultura.

O crecemento do arborado, pola súa parte, sería en parte o resultado da rexeneración natural pero sobre todo consecuencia da repoboación con fines de produción madeireira. Por exemplo como consecuencia das actuacións do antigo Patrimonio Forestal do Estado (PFE), activo entre os anos 1941 e 1971 e co período de máxima actividade entre 1952 e 1962. Aínda que os concellos da 
Terra Chá non foron dos máis afectados, a superficie repoboada nesta comarca entre 1941 e 1971 sitúase en torno ós $160 \mathrm{~km}^{2}$ (Rico Boquete, 1995). Tendo en conta que as actuacións se concentraron sobre montes veciñais non incluídos no Catálogo de Utilidade Pública, as repoboacións tiveron lugar principalmente sobre áreas que ata entón eran aproveitadas como mato para leña e pastoreo extensivo, como acreditan as protestas veciñais que suscitaron en numerosos casos. Polo tanto, esta actividade repoboadora está incluída fundamentalmente no cambio de mato a arborado e non de SAU a arborado, de xeito que este último debe responder sobre todo á repoboación por parte dos propietarios a título individual, e podemos supoñer que se deu maioritariamente nun momento moito máis cercano probablemente na década de 1990-, en grande parte ó abrigo das subvencións outorgadas precisamente para ese fin (García Arias \& Pérez Fra, 2001).

\section{Cambios por grupos de concellos}

As táboas 4, 5 e 6 mostran as diferentes direccións de cambio detectadas nos concellos. Para simplificar a comprensión, agrupamos os concellos en tres conxuntos baseándonos na evolución seguida pola SAU:

Grupo 1: concellos nos que diminuíu a porcentaxe de SAU (Begonte, Guitiriz, Muras e Vilalba).

Grupo 2: concellos nos que se mantivo a porcentaxe de SAU (Abadín, Castro de Rei, Cospeito e Xermade).
Grupo 3: concellos nos que se incrementou a porcentaxe de SAU (A Pastoriza).

Da comparación das táboas pódense destacar tres ideas principais. En primeiro lugar, o paso de SAU a mato é similar entre os tres grupos pero lixeiramente maior nos concellos nos que a SAU descendeu (grupo1). Sen embargo, o paso de SAU a arborado presenta diferencias máis importantes entre os tres grupos, aínda que reproduce a mesma tendencia (maior no grupo 1 que nos outros dous). Finalmente, e o que é máis importante, o cambio que presenta maiores diferencias entre os tres grupos é a roturación de terras de monte (paso de mato a SAU), practicamente se duplica do grupo 1 ó 2 (6,5\% e 12,6\% respectivamente) e ten moita importancia no grupo $3(18 \%)$. É dicir, semella que o factor determinante na diferente evolución da SAU nos concellos estudados non é tanto o abandono da terra (a expansión do mato por superficie anteriormente cultivada), senón á repoboación con fins madeireiros sobre áreas cultivadas (responsable da maior parte da expansión do arborado) e, sobre todo, a escasa actividade de roturación realizada nos concellos do grupo 1.

\section{A SAU e a evolución das explotacións}

Co fin de valorar ata que punto a evolución detectada se corresponde con outros datos dispoñibles, podemos comparala coa evolución do número de explotacións en cada un dos grupos de concellos xa definidos (táboa 7). Da

\begin{tabular}{|c|c|c|c|c|c|}
\hline \multirow[b]{2}{*}{$1956-57$} & \multicolumn{4}{|c|}{ 2003-04 } & \multirow[b]{2}{*}{ Total 1956-57 } \\
\hline & SAU & Mato & Arborado & Outras & \\
\hline SAU & $221(23,0 \%)$ & $76(7,9 \%)$ & $117(12,1 \%)$ & $19(2,0 \%)$ & $433(45,0 \%)$ \\
\hline Mato & $63(6,5 \%)$ & $217(22,5 \%)$ & $139(14,4 \%)$ & $13(1,4 \%)$ & $432(44,9 \%)$ \\
\hline Arborado & $17(1,7 \%)$ & $8(0,9 \%)$ & $51(5,2 \%)$ & $2(0,2 \%)$ & $78(8,1 \%)$ \\
\hline Outras & $5(0,5 \%)$ & $3(0,3 \%)$ & $7(0,7 \%)$ & $6(0,7 \%)$ & $21(2,1 \%)$ \\
\hline Total 2003-04 & $306(31,7 \%)$ & $304(31,6 \%)$ & $314(32,4 \%)$ & $40(4,3 \%)$ & $964(100 \%)$ \\
\hline
\end{tabular}

Táboa 4.- Transicións observadas entre 1956 e $2004\left(\mathrm{~km}^{2}\right)$, grupo 1

\begin{tabular}{|c|c|c|c|c|c|}
\hline \multirow{2}{*}{$1956-57$} & \multicolumn{4}{|c|}{ 2003-04 } & \multirow{2}{*}{ Total 1956-57 } \\
\hline & SAU & Mato & Arborado & Outras & \\
\hline SAU & $209(30,7 \%)$ & $35(5,2 \%)$ & $56(8,2 \%)$ & $13(2,0 \%)$ & $313(46,0 \%)$ \\
\hline Mato & $86(12,6 \%)$ & $123(18,0 \%)$ & $85(12,5 \%)$ & $6(0,9 \%)$ & $300(44,0 \%)$ \\
\hline Arborado & $17(2,5 \%)$ & $5(0,8 \%)$ & $26(3,8 \%)$ & $3(0,4 \%)$ & $51(7,5 \%)$ \\
\hline Outras & $5(0,7 \%)$ & $3(0,4 \%)$ & $2(0,3 \%)$ & $9(1,2 \%)$ & $19(2,6 \%)$ \\
\hline Total 2003-04 & $317(46,6 \%)$ & $166(24,4 \%)$ & $169(24,7 \%)$ & $31(4,4 \%)$ & $685(100 \%)$ \\
\hline
\end{tabular}

Táboa 5.- Transicións observadas entre 1956 e 2004 (km²), grupo 2

\begin{tabular}{|c|c|c|c|c|c|}
\hline \multirow{2}{*}{$1956-57$} & \multicolumn{4}{|c|}{ 2003-04 } & \multirow{2}{*}{ Total 1956-57 } \\
\hline & SAU & Mato & Arborado & Outras & \\
\hline SAU & $62(35,2 \%)$ & $8(4,5 \%)$ & $9(5,0 \%)$ & $3(1,8 \%)$ & $82(46,5 \%)$ \\
\hline Mato & $33(18,7 \%)$ & $24(13,7 \%)$ & $23(12,7 \%)$ & $2(1,4 \%)$ & $82(46,5 \%)$ \\
\hline Arborado & $3(1,8 \%)$ & $0(0,0 \%)$ & $3(1,8 \%)$ & $0(0,0 \%)$ & $6(3,7 \%)$ \\
\hline Outras & $3(2,0 \%)$ & $1(0,4 \%)$ & $0(0,3 \%)$ & $1(0,4 \%)$ & $5(3,1 \%)$ \\
\hline Total 2003-04 & $101(57,7 \%)$ & $33(18,7 \%)$ & $35(19,8 \%)$ & $6(3,8 \%)$ & $175(100 \%)$ \\
\hline
\end{tabular}

Táboa 6.- Transicións observadas entre 1956 e 2004 (km²), grupo 3 


\begin{tabular}{ccc}
\hline Grupo & $\begin{array}{c}\text { Var. do } n^{\circ} \text { de explotacións } \\
(1962-1999)\end{array}$ & Relación SAU/ST en 1999 \\
\hline 1 & $-36,8 \%$ & $45,2 \%$ \\
2 & $-29,8 \%$ & $57,1 \%$ \\
3 & $-27,1 \%$ & $72,4 \%$ \\
\hline
\end{tabular}

Táboa 7.- Evolución do número de explotacións e aproveitamento da superficie total. Fonte: elab. propia a partir de INE (1963, 2008a)

comparación pódese apreciar que foi nos concellos do grupo 1 onde o peche de explotacións foi máis acusado, o que é coherente coa bibliografía (López Iglesias, 1996). Por outra parte, para avaliar que tipo de aproveitamento realizan as explotacións sobre a súa superficie, e tendo en conta que non se dispón de datos de SAU por explotación para o censo de 1962, utilizamos a relación entre SAU e superficie total (SAU/ST) correspondente a 1999 (táboa 6). Como se pode observar, os valores son maiores para os grupos $2 \mathrm{e}$ 3 , o que está relacionado coa relativa importancia -en termos de superficie- da transición de mato a SAU detectada nas matrices de cambio nestes grupos (táboas 4 , 5 e 6). Este feito indica que moitas das explotacións destes concellos incrementaron a súa SAU mediante a roturación, para usos máis intensivos, de superficies de mato da súa propiedade, e corrobora o maior peso da transición de mato a sau detectada no traballo.

Un dos factores que puido facilitar ese mellor aproveitamento da superficie das explotacións (especialmente no grupo 3 formado por A Pastoriza) é a concentración parcelaria: destaca o feito de que A Pastoriza sexa o concello da comarca con máis superficie concentrada en 1999 (22 zonas de actuación e máis de 13.000 ha afectadas), seguida de Castro de Rei (5 zonas de actuación) e con bastante menor importancia no resto (Crecente Maseda et al., 2001).

\section{Conclusións}

Os resultados mostran que a SAU comarcal descendeu levemente entre 1956 e 2004: do $44,5 \%$ ó $39,8 \%$ da superficie comarcal. Non obstante, débese ter en conta que dentro do marco do sistema agrario imperante en 1956 o concepto de superficie utilizada pola agricultura incluía non só a terra arable e os prados e pasteiros senón tamén unha boa parte da superficie de mato (que en 1956 ocupaba arredor do $45 \%$ da superficie comarcal). Nese sentido podemos afirmar que o descenso de superficie agrícola en sentido amplo tivo que ser moito máis marcado. En todo caso o descenso de SAU é o resultado de tres cambios de uso en sentidos diferentes: aqueles que actúan diminuíndo a súa superficie (de SAU a mato, de SAU a arborado) e o que actúa incrementándoa (de mato a SAU). O balance das transferencias entre a SAU e o mato foi favorable á primeira, revelando que foi maior a superficie de mato roturada para usos agrícolas que a SAU que evolucionou a mato como consecuencia do abandono. O caso das transferencias entre SAU e arborado é diferente, xa que é case anecdótico o caso da superficie arborada que pasa a ser utilizada pola agricultura pero moi importante a superficie agrícola que se cubre de arborado ( $10 \%$ da superficie comarcal).
O traballo confirma a complexidade espacial do proceso ó detectar diferencias importantes na evolución seguida pola SAU nos distintos concellos que forman a comarca: os resultados permiten detectar a presencia de concellos nos que a SAU descendeu durante o período estudado, xunto a outros nos que se mantivo estable ou incluso se incrementou (o caso particular do concello da Pastoriza). A diferente evolución entre concellos parece ser gobernada fundamentalmente por dous tipos de cambio: o paso de SAU a arborado, e o paso de mato a SAU, que a grandes rasgos se corresponden coa repoboación forestal e coa roturación de terras de monte para uso agrícola (reflectida na relación SAU/ST). Interesa resaltar que foi o cambio de uso voluntario por parte do propietario e non o simple abandono da terra, o factor que máis afectou ó descenso de SAU. Por outra parte, tamén se demostra que o descenso local de SAU se pode producir incluso nunha comarca considerada moi productiva, e cunha clara especialización gandeira, como é o caso da Terra Chá.

En resumo, o traballo confirmou que máis alá das variacións que a superficie agrícola experimente a nivel rexional, é necesario ter en conta a gran variabilidade espacial do fenómeno. Demóstrase que o descenso local de SAU se produciu incluso nunha comarca considerada moi produtiva. En consecuencia, as medidas encamiñadas a contrarrestar o proceso de perda de SAU e as súas consecuencias negativas beneficiaríanse en grande medida dunha planificación espacial que dirixa a súa atención cara as áreas nas que esta é máis necesaria. É evidente a necesidade doutros estudios que, tamén desde o punto de vista territorial, completen esta análise e, en particular, fagan máis fina a escala temporal de traballo.

Agradecementos Os autores queren expresar o seu agradecemento á Dirección General de Medio Natural y Política Forestal, e en particular ó Dr. Enxeñeiro de Montes D. Roberto Vallejo, polas facilidades para acceder ós seus fondos.

\section{Referencias}

Baldock, D., Beaufoy, G., Brouwer, F. Godeschalk (1996). Farming at the margins: abandonment or redeployment of agricultural land in Europe. Institute for European Environmental Policy, London/The Hague.

Bouhier, A. (2001). Galicia. Ensaio xeográfico de análise e interpretación dun vello complexo agrario. Biblioteca de Clásicos Agrarios Galegos, vol. XVI (trad. do orixinal de 1979), Consellería de Agricultura, Gandería e Política Agroalimentaria (Xunta de Galicia). 
Calvo Iglesias, M. S. (2005). Characterization and dynamics of the cultural landscapes in Galicia with GIS and remote sensing tools for planning and management. Application in a Northern area of the province of Lugo. Tese Doutoral. Universidade de Santiago de Compostela.

Cardesín Díaz, J. M. (1987). Política agraria y transformaciones en la agricultura gallega: la zona de colonización de Terra Chá (1954-1973), Agricultura y Sociedad, 44: 243-280.

Corbelle Rico, E., Gil Docampo, M. L., Armesto González, J. Rego Sanmartín, T. (2006). La escala cartográfica de la imagen de satélite. Caso particular de las imágenes Ikonos y Quickbird, Revista de teledetección, 26: 18-23.

Crecente Maseda, R., Fra Paleo, U., Álvarez López, C. (2001). Concentración parcelaria en Galicia. Caracterización e avaliación. Consellería de Agricultura, Gandería e Política Agroalimentaria, Xunta de Galicia, Santiago de Compostela.

DLG (2005). Land abandonment, biodiversity and the CAP. Dienst Landelijk Gebied (Government Service for Land and Water Management of the Netherlands), Utrecht.

EEA (2004). High nature value farmland. Characteristics, trends and policy challenges. European Environment Agency. Report nº 39 (1/2004), Luxembourg.

Fernández García, F., Quirós Linares, F. (1997). El vuelo fotográfico de la "Serie A". Ería, 43: 190-198.

García Arias, A. I., Pérez Fra, M. (2001). Análise e evolución da aplicación en Galicia do programa de axudas á reforestación de terras agrarias (Reg. CEE 2080/92). Revista Galega de Economía, 10, 1: 151-176.

Iglesias Patiño, C. L., López Vizcaíno, M. E., Sánchez Fernández, P. (2000). Dimensionalidade da capacidade económica nas comarcas galegas. Revista Galega de Economía, 9, 2: 67-90.

Instituto Nacional de Estadística (1963). Primer Censo Agrario de España. Año 1962. Resultados provisionales. Segunda parte: datos municipales. INE, Madrid.

Instituto Nacional de Estadística (2008a). Censo Agrario 1989 y 1999, URL: http://www.ine.es.

López Charques, R. (1997). Estudio socioeconómico de Terra Chá. Servizo de publicacións da Deputación Provincial de Lugo.

López Iglesias, E. (1996). Movilidad de la tierra y dinámica de las estructuras agrarias en Galicia. Ministerio de Agricultura, Pesca y Alimentación, Secretaría General Técnica, Madrid.
López Iglesias, E. (2000). O sector agrario galego ás portas do século XXI: balance das súas transformacións recentes. Revista Galega de Economía, 9, 1: 167-196.

MacDonald, D., Crabtree, J. R., Wiesinger, G., Dax, T., Stamou, N., Fleury, P., Gutiérrez Lazpita, J., Gibon, A. (2000). Agricultural abandonment in mountain areas of Europe: Environmental consequences and policy response. Journal of Environmental Management 59: 47-69.

Martino, L. Fritz, M. (2008). New insight into land cover and land use in Europe. Land Use/Cover Area frame statistical Survey: Methodology and Tools. Eurostat Report (Statistics in focus) $33 / 2008$.

Millington, J. D., Perry, G. L., Romero Calcerrada, R. (2007). Regression techniques for examining land use/cover change: a case study of a Mediterranean landscape. Ecosystems, 10, 4: 562-578.

Ministerio de Agricultura, Pesca y Alimentación (1981-2004). Anuario de Estadística Agraria 1980 (1981), Anuario de Estadística Agraria 1989 (1990), Anuario de Estadística Agroalimentaria 2003 (2004). Madrid.

Ministerio de Agricultura, Pesca y Alimentación (2002). Metodología para la elaboración del SIGPAC. Anexo I: Recomendaciones técnicas para la generación de las ortofotos digitales del Sistema de Identificación de Parcelas Agrícolas. Documento técnico interno.

Mottet, A., Ladet, S., Coqué, N., Gibon, A. (2006). Agricultural land-use change and its drivers in mountain landscapes: a case study in the Pyrenees. Agriculture, Ecosystems and Environment, 114, 296-310.

Rico Boquete, E. (1995). Política forestal e repoboacións en Galicia (1941-1971). Servicio de Publicacións e Intercambio Científico, Universidade de Santiago de Compostela.

Strijker, D. (2005). Marginal lands in Europe - causes of decline. Basic and Applied Ecology, 6: 99-106.

Xunta de Galicia (2003). Anuario de Estatística Agraria 2002. Consellería de Agricultura, Santiago de Compostela.

van Doorn, A. M., Bakker, M. M. (2007). The destination of arable land in a marginal agricultural landscape in South Portugal: an exploration of land use determinants. Landscape ecology, 22, 1073-1087. 